\section{Density of Water sorbed on Montmorillonite}

IN a recent communication, Anderson and Low ${ }^{1}$ have described some investigations indicating that the water present in Wyoming bentonite (montmorillonite) pastes has a density lower than that of liquid water. It should be noted, however, that this does not preclude the water sorbed in the primary process having a close-packed structure around the ions $^{2}$, and consequently having a much higher density. For example, for monovalent or divalent ions the amount of such water would only be some 4 or 12 molecules, respectively, per ion, and if the additional sorbed water were considered to have, say, the hexagonal-net structures, the density of which would be about 0.9 , the value for the density of the sorbed water would drop rapidly at water contents above about 7-10 per cent, and for pastes with 60 per cent water ${ }^{1}$ could easily be less than unity. Such a decrease in density of sorbed water is well shown by the results of De Wit and Arens ${ }^{4}$, who obtained values as high as 1.41 at 11.6 per cent moisture, dropping to 0.997 above 30 per cent. Somewhat similar results were obtained in this Institute some time ago using a density-bottle technique with a specially devised de-airing procedure and 'Dekalin' as the non-sorbed liquid. Values ranging from about 1.38 at 9 per cent water to about 1.06 at 20 per cent water were obtained-in substantial agreement with the results of $\mathrm{De}$ Wit and Arens'.

The validity of any results for the density of sorbed water are, however, extremely difficult to assess, since every value must necessarily involve the volume of the sorbed water, and this has to be estimated on the assumption that the amount of swelling of the mineral represents the volume of this water. Irrespective of water content, this can only be true if the surfaces of the individuel mineral layers are impermeable. It is well known, however, that the layer surfaces of montmorillonite are not continuous but consist of a hexagonal network of oxygen ions with holes of approximate radius $1 \cdot 3 \mathrm{~A}$. On complete removal of water, ions can, at least partially, fit into these holes. Furthermore, recent unpublished work with montmorillonite saturated with various cations suggests that the oxygen ions of $\mathrm{UO}_{a}^{2+}$ may, to some extent, fit into the holes when the mineral is in the collapsed condition (ef. the results of Nuss and $W_{e y}{ }^{5}$ ). It is reasonable, therefore, to suppose that at least some water molecules may find their way into such holes, and thus have an apparent density approsching infinity. This factor would influence results whether clay pastes or clay powders are used, and all results must be influenced thereby. It is not possible at present to determine the magnitude of error likely to arise from this cause, or even to decide whether it is appreciable. The fact that montmorillonite equilibrated at 0 per cent relative humidity has, according to De Wit and Arens, a higher density than clay oven-dried to 0.0 per cent moisture, cannot be used as an estimate of the size of the effect, since (although no details are given) it is likely that the oven-drying was carried out at $105^{\circ} \mathrm{C}$. when a few per cent of sorbed water was still present. In the results obtained at this Institute drying at $190^{\circ} \mathrm{C}$. was employed.

Another factor only operative at low water contents is the assumption that the layers are sufficiently flexible to fit closely around the interlayer water 'islands'. Any departure from this condition would tend to act in the opposite way from the above effect and give low values. The magnitude of the error likely to arise from this factor is also unknown, but the two opposing tendencies cannot balance since this error becomes less the higher the proportion of water.

From the above considerations, it would appear that no very useful conclusions regarding interlayer water configuration can yet be drawn from density measurements.

Robert C. MaCkenzen

Macaulay Institute for Soil Research, Craigiebuckler, Aberdeen. Dec. 26.

1 Anderson, D. M., and Low, P. F., Nature, 180, 1194 (1957),

${ }^{2}$ Mackenzie, R. C., Clay Min. Bull., 1, 115 (1950),

${ }^{3}$ Hendricks, S. B., and Jefferson, M. S., Amer. Min., 23, 863 (1938). Hendricks, S. B., Nelson, R. A., and Alexander, L. T., J. Amer. Chem. Soc., 62, 1457 (1940).

4 De Wit, C. T., and Arens, P. L., Trans. 4th Int. Congr. Soll Sci. Amsterdam, 2, 59 (1950).

${ }^{5}$ Nuss, M.-I., and Wey, R., Bull. Oroupe franc. Argiles, 7, 15 (1956).

\section{Amino-acids in Anthracite}

A TOPIC of current interest in palæo-biochemistry is the demonstration of chemical constituents in fossils from the earliest plant and animal life. It has been shown that bones of great archæological age may contain appreciable amounts of organic nitrogen $^{1,2}$. Even such highly organized compounds as amino-acids have been identified in fossil shells and bones ${ }^{8}$.

As a contribution to these investigations, it seemed worth while to analyse the protein remains in anthracite-one of the oldest fossils known.

The central part of a thoroughly rinsed piece of anthracite from a British mine was ground into a powder in a mortar. After drying, 100-mgm. aliquots of the powder were hydrolysed in ampoules with $6 N$ hydrochloric acid for $24 \mathrm{hr}$. at $100^{\circ} \mathrm{C}$. The hydrochloric acid was afterwards removed by means of freeze-drying. The residue was dissolved in distilled water, filtered to remove coal particles and evaporated in vacuo to dryness. The residue was redissolved in $0.2 \mathrm{ml}$. of distilled water. $100 \mu \mathrm{l}$. of the solution were applied to paper sheets (Whatman No. 4) for two-dimensional chromatography in phenol and colloidin-water systems according to Dent". The amino-acid spots revealed with ninhydrin were allowed to develop for $24 \mathrm{hr}$. in the dark and preserved by treatment with a solution of cupric nitrate in ethanol. The semi-quantitative estimations of the amino-acid content of the spots were made according to Dent4. The $\alpha$-amino-nitrogen content was determined by a method suggested by Woiwod ${ }^{5}$.

After two-dimensional paper chromatography, aspartic acid, glutamic acid and glycine could be demonstrated in the cosl samples. The semi-quantitative estimation showed a relative proportion of 12 per cent aspartic acid, 40 per cent glutamic acid and 48 per cent glycine. The $\alpha$-amino-nitrogen content was 0.12 per cent, which roughly corresponds to 1 per cent of amino-acids in the original anthracite sample.

Amino-acids have thus been demonstrated in fossils about 250 million years old. Because of the procedure used for the preparation, it is impossible to tell whether these amino-acids are free or the result of the hydrolysis of peptides, though it is highly probable that the source of the amino-acids was the 